\title{
Challenges for 2030 in maternal care, newborn and under 5 years old
}

\begin{abstract}
The objective is to emphasize the importance on the subject of maternal morbidity and mortality, newborns, children under 5 years old, to meet the goal of transformation in the 2030 agenda towards sustainable development. One of the objective is health and wellbeing in order to guarantee universal access to sexual and reproductive health services, including family planning, information and education, with the integration of cross-cutting public policies and legal norms that allow the attention of the health service for women (before pregnancy, during pregnancy and after), as well as newborns and before the age of five.
\end{abstract}

Keywords: maternal care, newborn, pregnancy, birth defects, neonatal infections, child health
Volume 7 Issue 4 - 202I

\section{Mauricio Reyna Lara}

Doctor in Law and Pedagogy, Professor at the Faculty of Law and the Faculty of Administration (UNAM)

Correspondence: Mauricio Reyna Lara, Doctor in Law and Pedagogy, Professor at the Faculty of Law and the Faculty of Administration (UNAM), Mexico, Email mreyna@unam.mx

Received: June 30, 2021 | Published: August 24, 2021

\section{Introduction}

The World Health Organization reports that in 2017 some 2.5 million children died in their first year of life, a similar figure to that of 2015 and states with current trends, that 30 million newborns will die during their first 28 days of life. life between 2017 and 2030; On September 19, 2019, the United Nations Inter-Institutional Group for the Estimation of Infant Mortality issued a report based on a statistic of the level of mortality in children under 5 years of age due to the economic situation of each household by country, being one of the most current studies to date; causes are neonatal infections, pneumonia, diarrhea, birth defects, and malaria among a few others. ${ }^{i}$

Among the recommendations made by working groups on the subject, the Global Strategy for the Health of Women, Children and Adolescents (2016-2030) can be considered: adolescent health "All States should reinforce the legal recognition of rights to health and through health, including sexual and reproductive health and rights, in their constitutions and other national legal instruments. Remedies for violations of these obligations should be effective. Sufficient financial and human resources should be allocated to formulate and apply legislative and policy measures and social initiatives in order to guarantee the exercise of the rights to health and through health and facilitate universal access to health care."'ii Concern placed on health law in its scope as discipline in charge of finding such an answer on the subject, "All States should apply legal measures, political and other to monitor and address social, gender and cultural norms and remove structural and legal barriers that undermine the human rights of women, children and adolescents. Priority must be given urgently to the development of national frameworks that prohibit and adequately punish gender-based violence, the elimination of female genital mutilation and child, early and forced marriage, and the removal of barriers that impede the enjoyment of health and rights. sexual and reproductive rights" iii Mexico implemented a monitoring within the National System of Statistical and Geographical Information (SNIEG) the National Survey of Demographic Dynamics (ENADID) 2018 , to identify the behavior, in the dynamics of maternal and child health; In 197068 infants died for every thousand births, in 2018 it was public that from 2015 to 2017 there were 15.6 children under 1 year of age for every 1000 births, they were taken from references to women between 15 and 54 years of age.
In the same survey in Mexico, the percentage distribution of women in the last pregnancy occurred, by type of delivery, in the period 2014 to 2018 there is: Caesarean section scheduled in 2014 (23.0\%) in 2018 (23.3\%); Emergency cesarean sections 2014 (23.2\%) and in $2018(22.8 \%)$; Normal delivery in $2014(53.8 \%)$ and in 2018 $(53.9 \%))^{\text {iv }}$

The General Director of Epidemiology of the Ministry of Health in Mexico, reports in week 25 of 2021, a calculation of 46.5 deaths per 100,000 estimated births, being the main causes of death of COVID-19, registering $149(34.2 \%)$ with confirmed SAR-Cov2 viruses. COVID-19, unidentified virus 17 (3.9\%). Edema, proteinuria and hypertensive disorders that complicate pregnancy, childbirth and the puerperium $(12.8 \%)$. The entities with the greatest incidents are: Edo. Mexico (68), Jalisco (32), CDMX (31), Puebla (24), and Chiapas (21). ${ }^{\mathrm{v}}$ Altogether they are $40.4 \%$ of registered deaths, the incidences continue to occur in the country. ${ }^{1-12}$

\section{Legislative results and obstacles}

In Mexico, in the text of Article 4 of the Political Constitution of the United Mexican States in force, it establishes the right to health protection and the reproductive decision to have children, in an informed and free manner; as well as in article 2 with the protection of the health of women of indigenous peoples; and in article 123 section "A" on the protection of women during pregnancy in the labor relationship and the recognition of the right to incapacity for work in relation to pregnancy, six weeks before and six after childbirth, preserving their full labor rights ; In the same article 123 of section "B", the maternity leave will be one month before and one month later with respect to childbirth, preserving the labor rights that it has, in addition to that during the lactation period, they will be able to have two breaks of 30 minutes a day, to feed your children; In addition to this right, for both sections of the employment relationship in question, private or public sector, the workers will enjoy medical and obstetric medical assistance, lactation assistance and childcare services.

The General Health Law regulates the right to health with maternal and child care, which is considered as a matter of general health (Art. 3 , section IV and 27, section IV), and maternal and child care with the character priority. 
In the same law (LGS) it is provided in its third title of Provision of Health Services, chapter V, of art. 61 to 66 on Maternal and Child care and from 67 to 71 on family planning. It should be noted that these provisions that will be described below are procedurally complementary with the Official Mexican Health Standard NOM007-SSA2-2016, For the care of women during pregnancy, childbirth and the puerperium, and the newborn person.

The object of maternal and child protection and the promotion of maternal health, which covers the period between pregnancy, childbirth, postpartum and puerperium, due to the vulnerability of the woman and the product. In women it includes the psychological care that they require and the transmission of HIV / AIDS and other Sexually Transmitted Infections, and in pregnant women in order to avoid perinatal transmission. Every pregnant woman has the right to obtain health services with strict respect for her human rights.

In the care of newborns, boys and girls: the monitoring of their growth, comprehensive development, including timely vaccination, prenatal care, as well as the prevention and detection of hereditary and congenital conditions and diseases, the application of the sieve test expanded, his visual health, revision of retina and hearing screening to the premature; the application of the neonatal ophthalmological screen, at the fourth week of birth, for the early detection of malformations that can cause blindness, and their treatment, in all its degrees. Timely diagnosis and early care of developmental dysplasia of the hip, through clinical examination in the first week after birth, in the first month of age and at two, four, six, nine and twelve months of age; as well as taking an ultrasound of the hip or ante-posterior pelvic X-ray, between the first and fourth month of life. Timely care for diarrhea and respiratory infections, especially in children under 5 years of age.

The health institution of the private, public and social assistance sectors will be obliged to promote the institutional organization of committees for the prevention of maternal and infant mortality, in order to know, systematize and evaluate the problem and adopt the appropriate measures. The health services for maternal and child care will promote a procedure in which the family participates in the prevention and timely care of the ailments of the users of the services. In addition to promoting breastfeeding and breastfeeding, encouraging that breast milk is exclusive food for six months and complementary until late in the second year of life and, where appropriate, direct food aid aimed at improving the nutritional status of the mother-child group, in addition to promoting the installation of lactation plants in the work centers of the public and private sectors. There must be a minimum milk bank for each federative entity, which the population conditions, according to the needs, may demand a greater number.

Develop capacities with the skills and technical competencies of traditional midwives, for the care of pregnancy, childbirth and the puerperium, especially in communities where they are far from having a formal medical service.

Create Support Networks for Maternal and Child Health, both at the federal level and in the states, in order to provide information to pregnant women about the services offered.

Create Support Networks for Maternal and Child Health, both at the federal level and in the states, in order to provide information to pregnant women about the services offered.

All obstetric emergencies must be attended regardless of their right, availability or affiliation to any type of insurance. The term of the law (LGS) in article 64 Bis, indicates that in an expeditious manner they will pay attention, the meaning of expedited, is: "From the Latin expeditus 1.adj. Unburdened, free from any hindrance.

adj. Soon to act." ${ }^{\mathrm{vi}}$ Without delay and economic and social condition, even more so when article 35 of the same law establishes universality and gratuity services to vulnerable groups at the time of requesting services, and the provisions of the same way by the referred law, in its article 55 that any person or public or private institutions that have knowledge of an emergency must be attended to and stabilized, without any condition involved.

The Official Mexican Health Standard NOM-007- SSA2-2016. For the care of women during pregnancy, childbirth and the puerperium, and the newborn person; which is mandatory throughout the national territory, in the public, social and private sectors in the National Health System, points out that in emergency obstetric care, health personnel must provide immediate and correct care continuously 24 hours a day, every day of the year, which occurs during pregnancy, childbirth or the puerperium, which conditions an imminent risk of maternal and perinatal morbidity or mortality. "The process begins with the activation of the Mater Code in the presence of a patient with obstetric emergency (red code) and ends when deciding the definitive management once the best possible stabilization has been achieved. The arrival time of the team should not be greater than three minutes after the Mater Code is activated."vii

And as a complement to this, we have an emergency in accordance with the Regulations of the General Health Law in Matters of Provision of Medical Care Services for immediate attention and in case of urgency. With this, it is completely more than clear that all obstetric emergencies must be attended in any institution of the National Health System in our country, a consideration that personnel who are in an emergency area of a hospital must have knowledge and training on the subject. hospital, or any institution or person that can help the patient. In addition to establishing in the same NOMS 007, referred to above, that in childbirth care "No person who provides gynecology and obstetrics services, will discriminate or exercise any type of violence against women in labor." "viii That it is not strictly speaking enunciatively in the law as obstetric violence as stated by the legislator of the Upper House of Mexico, Claudia Edith Anaya Mota, when proposing a draft decree that reforms various provisions of the General Law of Access of Women to a Life Free of Violence and the General Health Law, which coincides with the proposal published in the Parliamentary Gazette by the Gender Equality Commission; so that both provisions legally harmonize our National Health System in qualifying obstetric violence as institutional violence "Institutional violence, understood as the attitudes of discrimination, psychological and physical abuse and abandonment; practiced by health professionals, before women in their obstetric care, is a considerable risk factor for maternal death; especially in the context of indigenous and / or poor women, cared for in health institutions in both the public and private spheres. Also the inadequate attention to obstetric emergencies, represents a lack of guarantee of the rights of women and in itself, a form of gender violence. ${ }^{\text {ix }}$ The above, it is necessary to be regulated in the law to guide the incidence of maternal care - children as a priority and improve the quality of the service, legal regulation allows the identification of good behavior in the practice of health personnel with their due training on the subject as an obligation derived from the institutions to promote and promote it. It is necessary to reach 2030 with the commitment to have considerably reduced maternal and newborn mortality in our country.

This is the case of the legislation for the practice of responsible paternity, where the activities and care tasks are the responsibility 
of both, both the mother and the father; In our labor legislation of the Federal Labor Law of section A of article 123 of the Federal Constitution, it establishes in its article 132 fraction XXVII bis the obligation for the employer to grant paternity leave of 5 working days with pay, of the same way in the case of when it is in the adoption of an infant. Legislation sensitive to the integration of family roles that contribute to the health sensitivity of women and the newborn; however, it is not being enough. A disproportionate burden on women caring for children can prevent mothers from taking full-time jobs. It can also cause employers to discriminate in hiring women of childbearing age because of the risk that they will leave their position to care for children. children in the future." Study carried out by the Organization for Economic Cooperation and Development (OECD), in several countries, such as Mexico, which causes men in the workplace to become the provider and not the educator of their children. The explanation goes beyond a productive life only, but a life with greater value elements of principles in the family, the help and responsibility of training in the children must be a joint responsibility, between mother and father, responsibility in the state of women's health during and after pregnancy is a task that involves and makes both of them responsible, "Mexico must grant more than its current five-day paternity leave to parents, use public funds for the period of this leave, and incentivize parents to take the leave for which they are eligible." ${ }^{x}$

The commitment of the new labor legislation in Mexico must include, working paternity, prenatal and postnatal leave, with pay, recognition that they are taken from the common responsibility of men and women regarding the education and development of their children, as established in the Convention on the Elimination of All Forms of Discrimination against Women. "The time commitment required for many jobs - both in the private and public sectors - makes it difficult for parents to reconcile work with caring for the family. Long hours have negative effects on parents, who lose valuable time that could be with his family, and also with mothers, whose chances of leaving the labor market to care for their children are greater. " $k$ Health concerns about maternal and child care are combined with public policies for health, education and employment; actions from the community and the family that contribute to reducing this problem of mortality and violence. Improving water services and physical activity of the population are inclusive issues of public health policy in maternity and care of newborns, boys and girls.

Carrying out school monitoring of the physical and emotional state of children in nurseries and schools is an obligation for private and public institutions; that they must attend daily, at their reception and during their storage in the educational institution, completing with cooperatives and dining rooms with nutritious diets.

Pregnant or breastfeeding women, newborns, boys and girls are considered vulnerable and risk groups, so the State must guarantee consistent actions in providing food aid to groups or communities that need it, in addition to promoting production. of sufficient and quality food. Hence, an International Code of Marketing of Breast-milk Substitutes was promoted by the World Health Organization in 1981, to protect from the inappropriate marketing of breast-milk substitutes, thereby prohibiting the public dissemination of formulas, of under 6 months and in an excessive way, since the essential thing is to have the attachment and natural breastfeeding of the mother; Mexico has such legal control provisions, the last publications on the subject were in 2018 , on the guide to good practices in breast milk substitutes in hospitals.

\section{Conclusion}

It is necessary to establish community and transversal public policies on the issue of sexual reproduction, maternity, newborns and children under 5 years of age in health, education and labor rights, which can be easily identified and according to the roles of Mexican society, with greater relevance from COVID-19.

The training of health personnel on international and national strategies and standards for the entire sector of the National Health System, encompassing current regulations on the quality of care in health services in sexual reproduction, maternity, newborns and minors of 5 years. According to the data provided by the General Directorate of Epidemiology of the Ministry of Health in Mexico, in 2021, emphasizing the states with the highest incidence of maternal deaths should make greater efforts. The publication on the subject to highlight the importance and need to create, adapt and modify norms, regulations, laws that contain the standards and strategies recommended by the World Health Organization, by institutions, health personnel and pregnant women together with the family, who are asked to give continuity to reduce the incidence of maternal mortality, newborns and children under 5 years of age.

Within the 2030 agenda is the health and well-being of the population of all ages, however, this article highlights the importance of the cases with the highest incidence of vulnerable groups, pregnant women and children under 5 years of age, the Organization World Health Organization (WHO), the Pan American Health Organization and the United Nations Children's Fund (UNICEF) report that more than 6 million children under 5 years of age continue to die each year, and only half of all women in developing regions have access to the healthcare they need. Accountability to improve the quality of health services is essential.

\section{Acknowledgments}

None.

\section{Conflicts of interest}

There is no conflict of interest in this article.

\section{Funding}

None.

\section{References}

1. OECD. Buildingan Inclusive Mexico, Policies and Good Governance for Gender Equality, OECD Publishing, Paris; 2017.

2. Ministry of Health, National Center for Gender Equity and Reproductive Health, Manual: Obstetric Triage, Mater Code and Immediate Obstetric Response Team, Technical Guidelines, Mexico; 2016.

3. Tinoco Zamudio MT. Proposal for the prevention and care of institutional violence in obstetric care in Mexico, Conamed Magazine. 2016;21(supplement 1).

4. Evolution of maternal mortality: 1990-2015. 2019.

5. Global Strategy for Women's and Children's Health. 2019.

6. Parliamentary Gazette of the Chamber of Deputies. 2019.

7. INEGI National Survey of Demographic Dynamics 2018. 2019.

8. The report. entitled Levels and Trends in Child Mortality 2017. 
9. Global Strategy for the Health of Women, Children and Adolescents (2016-2030). 2017.

10. Report: National and regional mortality rate of children under 5 years of age.

11. General Health Law. 2019.

12. Directorate of Epidemiological Surveillance of Non communicable Diseases.

\section{Endnotes}

i. Newborns: improving survival and well-being. 2019

ii. Global Strategy for Women's Health the Child and the Adolescent (2016-2030): adolescent health. 2017.

iii. Ibídem.

iv. Ibídem.

v. Weekly publication by the Directorate of Epidemiological Surveillance of Noncommunicable Diseases. Current Publication. 2021. vi. Dictionary of the Spanish Language, tricentennial edition, Royal Spanish Academy. 2019.

vii. Ministry of Health, National Center for Gender Equity and Reproductive Health, Obstetric Triage, Mater Code and Immediate Obstetric Response Team, Technical Guidelines, Mexico; 2016. 37 p.

viii. Official Mexican Health Standard NOM-007- SSA2-2016, For the care of women during pregnancy, childbirth and the puerperium, and the newborn. 2019.

ix. Tinoco Zamudio MT. Proposal for the prevention and care of institutional violence in obstetric care in Mexico. Conamed Magazine. 2016;21(Suppl 1):48-54.

x. Ibídem. p. 44. 